\title{
Heparin Induced Thrombocytopenia: Can Be Excluded
}

Dr Nissar Shaikh

Department of Anesthesia/ICU, Hamad Medical Corporation, Doha-Qatar

\begin{abstract}
Thrombocytopenia is common in the hospitalized patients. Heparin induced thrombocytopenia (HIT) can be defined as clinicopathological procoagulant condition with thrombocytopenia in patients on heparin therapy Platelet count of less than 100,000 or decrease by $50 \%$ of the base line value from $5-14$ days of heparin therapy. In rare case HIT can occur before 5th day or after the 14th day or even after stopping the heparin therapy.

HIT is a known but rare complication of heparin therapy. It is a potentially life and limb threatening, prothrombotic coagulation disorder associated with significant increased in the morbidity and mortality. Early and accurate diagnosis or exclusion of HIT is the corner stone in the management of these patients; as the over diagnosis will result in use alternative anticoagulant with increased bleeding risk or under diagnosis or delayed diagnosis will leaves patient vulnerable for the development of thrombosis.

HIT have a unique pathophysiology and testing, and a low 4 ' $T$ ' Score, lateral flow immunoassay (LFIA) can rule-out HIT in 10 minutes. It has a unique complication profile: Thromboemboli, and unique management with the alternative anticoagulants; It is a unique thrombocytopenia, where the risk of thrombosis is more than that of bleeding
\end{abstract}

Keywords: Heparin induced thrombocytopenia; Lateral flow immunoassay; Alternative anticoagulation

\section{Introduction}

Heparin is the most commonly used anticoagulant in the clinical practice over more than 7 decade. It is one of the most frequently used Parenterally administered medication in the hospitalized patients [1]. Heparin is a strong negatively charged polyaion with a molecular weight of 3000 to 30,000 Daltons.

Heparin induced thrombocytopenia (HIT) is a known but rare complication of heparin therapy. It is a potentially life and limb threatening, prothrombotic coagulation disorder associated with significant increased in the morbidity and mortality. Early and accurate diagnosis or exclusion of HIT is the corner stone in the management of these patients; as over diagnosis will result in use alternative anticoagulant with increased bleeding risk or under diagnosis or delayed diagnosis will leaves patient vulnerable for the development of thrombosis.

\section{Case}

A 19 year male driver involved in road traffic accident had isolated fracture shaft of femur. No any history of loss of consciousness, initial computerized tomography (CT) of head, chest and abdomen was normal. Immediately fracture was fixed with intramedullary nail. Perioperative period was uneventful. After 10 hours of surgery, family noticed that he had incoherent speech, and tachypnea; immediate examination revealed that he is drowsy, tachypnea (4050/Minute) tachycardia (130-150/minute) oxygen saturation of $60 \%$; bilateral cripitations. Chest $\mathrm{x}$-ray showed bilateral diffused infiltrates. Diagnosed as fat embolism syndrome; intubated added LMWH to the treatment and shifted to the intensive care unit. CT chest and brain revealed bilateral alveolar opacities and early brain edema respectively. $\mathrm{He}$ was in acute respiratory distress syndrome, remained on inverse ratio mechanical ventilation and had thrombocytopenia $(70,000)$, HIT antibody test was requested; by day 3 he was improving clinically his chest condition was much better, but surprisingly HIT antibodies test came as positive. Functional assay lateral flow immunoassay test (LFIA) was not available. We reviewed patient's clinical probability of HIT by 4
'T' score; he had a low probability of HIT. HIT was excluded, LMWH was continued. Gradually he improved; weaned and extubated by day 8 , transferred to the ward on day 10 from there discharged home.

\section{Definition}

Thrombocytopenia is common in the hospitalized patients. Heparin induced thrombocytopenia can be defined as clinicopathological procoagulant condition with thrombocytopenia in patients on heparin therapy. Platelet count of less than 100,000 or decrease in the platelet count by $50 \%$ of the base line value from 5-14 days of heparin therapy [2]. In rare case HIT can occur before 5th day or after the 14th day or even after stopping the heparin therapy [3].

\section{Epidemiology}

HIT is inderrcognized and underreported, the reported incidence of HIT is ranging from 1 to $5 \%$ of the patients on unfractionated heparin and thrombocytopenia [4]. But up to $8 \%$ of the patients on heparin therapy develop HIT antibodies and the incidence of HIT varies with type and duration of heparin use; HIT is 10 times more common with unfractionated heparin in comparison to the LMWH. It is more common in female patients. The incidence of HIT is higher in surgical than the medical patients, incidence are higher in cardiovascular and orthopedic patients, it is lower in obstetric patients [5].

\section{Risk factors}

The use of unfractionated heparin increases the risk of HIT, large

*Corresponding author: Dr Nissar Shaikh, Department of Anesthesia/ICU, Hamad Medical Corporation, Doha-Qatar, E-mail: nissatfirdous99@gmail.com

Received November 01, 2011; Accepted November 25, 2011; Published November 28, 2011

Citation: Shaikh N (2011) Heparin Induced Thrombocytopenia: Can Be Excluded. J Blood Disord Transfus S2:001. doi:10.4172/2155-9864.S2-001

Copyright: @ 2011 Shaikh N, et al. This is an open-access article distributed under the terms of the Creative Commons Attribution License, which permits unrestricted use, distribution, and reproduction in any medium, provided the original author and source are credited. 
intravenous unfractionated heparin dose, bovine heparin, surgical and female patients [6].

\section{Classification}

HIT is divided into two types depending on whether immunologically mediated or not; Type 1 also called as heparin associated thrombocytopenia and not caused by the development of antibodies but related to the large heparin dose. It occurs with first few day of heparin therapy and not associated with thromboembolism. Type 1 HIT is a self limiting condition [7]. (Table1) As heparin is a strongly negatively charged anion, binds with the positively charged platelet leading to thrombocytopenia. It occurs in first three days of heparin therapy and decrease in platelet count is not more than $30 \%$ of the baseline value [8]. Type 2 HIT is an immunologically mediated thrombocytopenia caused by the heparin dependent antibodies, it is further subdivided into (i) heparin antibodies development without any thrombocytopenia (ii) development of thrombocytopenia and heparin antibodies. (iii) HIT thromboembolic syndrome or HIT with white clot thrombosis, as there is lack of red blood cells in the clot and thrombosis occurs due to the complex formation of platelets and immunoglobin [9].

Type 2 HIT commonly occurs from 5 to 14 days of heparin therapy, it can occur earlier if patient had an exposer to heparin in last 3 months. Delayed HIT occurs even after heparin is stopped, as the B-cell which needs at least 5 days for sufficient antibodies production. Type2 HIT is potentially limb and life threatening condition requiring early diagnosis and an earlier alternative anti-coagulation therapy (Table 1).

\section{Pathophysiology}

The pathophysiology of type 1 HIT is simple, as negatively charged heparin on initiation of the therapy binds to positively charged platelets leading to mild thrombocytopenia. Whereas the pathophysiology of type 2 HIT is a complex immunologically mediated process; resulting in severe thrombocytopenia as well as generation large quantity of thrombin and leading to thromboembolism.

In type $2 \mathrm{HIT}$, heparin will bind with platelet factor 4 (PF4) and

\begin{tabular}{|c|c|c|c|}
\hline 4T's & 2 points & 1 point & 0 point \\
\hline Thrombocytopenia & $\begin{array}{l}\text { Platelet count fall } \\
>50 \% \text { and platelet } \\
\text { nadir } \geq 20^{*}\end{array}$ & $\begin{array}{l}\text { Platelet count fall } \\
30-50 \% \text { or platelet } \\
\text { nadir } 10-19\end{array}$ & $\begin{array}{l}\text { Platelet count fall } \\
<30 \% \text { or platelet } \\
\text { nadir }<10\end{array}$ \\
\hline $\begin{array}{l}\text { Timing of platelet } \\
\text { count fall }\end{array}$ & $\begin{array}{l}\text { Clear onset be- } \\
\text { tween days } 5-10 \\
\text { or platelet fall } \leq 1 \\
\text { day (prior heparin } \\
\text { exposure within } 30 \\
\text { days) }\end{array}$ & $\begin{array}{l}\text { Consistent with days } \\
5-10 \text { fall, but not } \\
\text { clear (e.g. missing } \\
\text { platelet counts); } \\
\text { onset after day } 10^{\ddagger} ; \\
\text { or fall } \leq 1 \text { day (prior } \\
\text { heparin exposure } \\
30-100 \text { days ago) }\end{array}$ & $\begin{array}{l}\text { Platelet count fall } \\
<4 \text { days without } \\
\text { recent exposure }\end{array}$ \\
\hline $\begin{array}{l}\text { Thrombosis or } \\
\text { other sequelae }\end{array}$ & $\begin{array}{l}\text { New thrombosis } \\
\text { (confirmed); skin } \\
\text { necrosis§; acute } \\
\text { systemic reaction } \\
\text { postintravenous un- } \\
\text { fractionated heparin } \\
\text { (UFH) bolus }\end{array}$ & $\begin{array}{l}\text { Progressive or recur- } \\
\text { rent thrombosis }{ }^{\pi} ; \\
\text { Non-necrotizing } \\
\text { (erythematous) skin } \\
\text { lesions } \S \text {; Suspected } \\
\text { thrombosis (not } \\
\text { proven)** }\end{array}$ & None \\
\hline $\begin{array}{l}\text { Other causes for } \\
\text { thrombocytopenia }\end{array}$ & None apparent & Possible $^{\dagger \dagger}$ & Definite $^{\dagger+}$ \\
\hline
\end{tabular}

Table 1: Pretest scoring system for HIT: the 4 T's. forms an immunological antigen, which stimulates generation of antibodies. This heparin $+\mathrm{PF} 4$ and IgG complex, will bind to the FC receptor site on platelets. (Figure 1) These process results in platelet activation. Heparin interaction with PF4 depends on molecular weight of heparin, longer and more sulfated unfractionated heparin chains are more immunological, hence wrap more PF4 particles compared to the LMWH; hence more risk for development of HIT.

HIT pathophysiology can be summarized in three steps; the initial step is generation of antibodies, second step is platelet activation and thrombin generation (this stage is potentially procoagulant) and stage is thrombus formation. Hypercoagulant/procoagulant condition in HIT is multifactorial, loss anticoagulation effect of heparin, platelet activation, microparticle in the circulation, increased thrombin generation and activation of intrinsic factors [10].

\section{Diagnosis}

Diagnosing HIT is a challenge, as the suffering patients will often have other reasons for thrombocytopenia. HIT is a clinicopathological condition, hence it is diagnosed by clinical probability (4'T' score) and presence of HIT antibodies. Clinical probability of HIT in a suscepected patient can be evaluated by 4 ' $\mathrm{T}$ ' score. (Table 2) This score is depending on severity and timing of thrombocytopenia in relation to heparin therapy, presence or absent of the thrombus and other etiological reasons for thrombocytopenia. If this score is less than 3 , there will be low probability for HIT and if it is above 6, there will be high probability for HIT and score of 4-5 will show intermediate probability for HIT [11]. If clinical probability with 4'T' score is low, it will rule-out HIT [11].

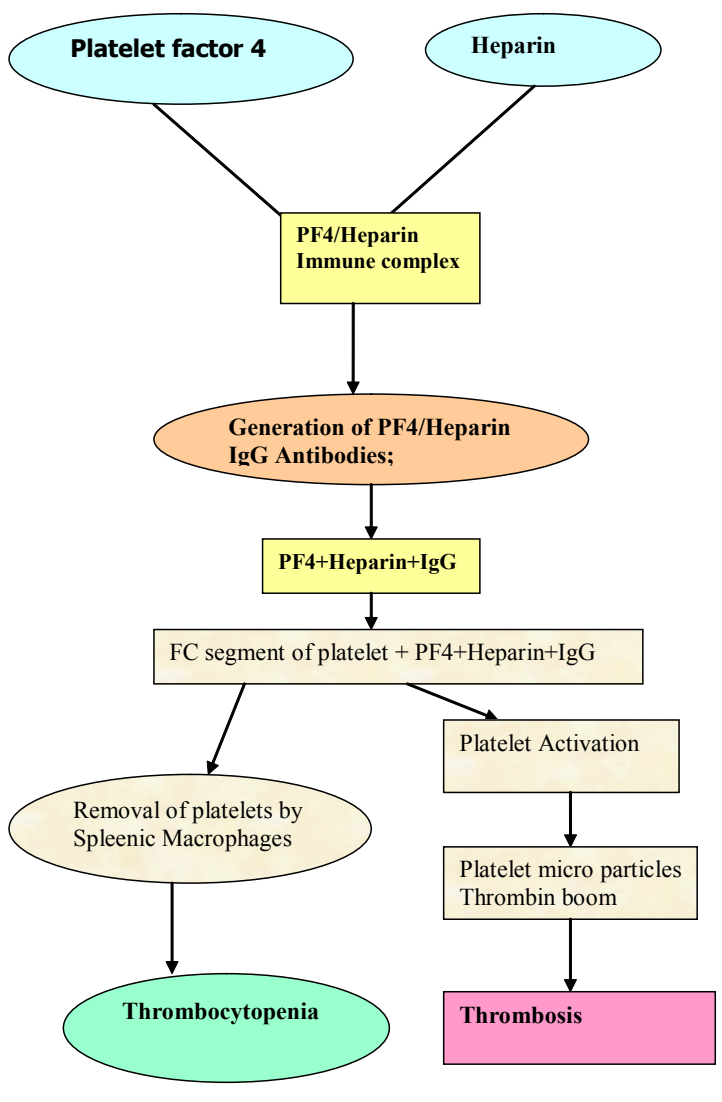

Figure 1: Immunology of HIT 


\begin{tabular}{|l|l|l|}
\hline \multicolumn{1}{|c|}{ HIT } & \multicolumn{1}{c|}{ TYPE1 } & \multicolumn{1}{c|}{ Type2 } \\
\hline Common occurrence & Initial 4 days & $\begin{array}{l}5 \text { to 14days of Heparin } \\
\text { therapy }\end{array}$ \\
\hline Thrombocytopenia & $<30 \%$ & $>50 \%$ \\
\hline Immune mediated & No & Yes \\
\hline Complications & None & Thromboembolism \\
\hline Therapy & Self limiting & $\begin{array}{l}\text { Needs alternative antico- } \\
\text { agulation }\end{array}$ \\
\hline
\end{tabular}

Table 2: Clinical probability of HIT in a suspected patient evaluated by 4 'T' score.

There are two well known methods to detect the HIT antibodies. First is functional assay; this includes serotonin release assay (SRA) and heparin induced platelet aggregation assay (HIPA). Second method is immunoassay, which able to detect the antibodies that bind to heparinPF4 complex but without any regards to their functional abilities [12]. Recently third method is introduced for diagnosis of HIT by lateral flow immunoassay (LFIA).

It is of vital importance that clinicians must be aware of the strength and weakness of all these available tests so as to take proper clinical decisions.

The functional assays are the gold standard for diagnosing HIT. But these assays are not available easily and it requires highly skilled technicians, pool of normal platelets and time consuming more over SRA requires radioisotopes, which many laboratories are avoiding due to regulation and the safety issues.

The enzyme -linked immunoassay, is commonly used to detect HIT antibodies, as these tests are simple, technically easy to perform, not needed normal platelets, and radioisotopes. These test are highly sensitive (100\%) but not specific (80\%); hence there are chances that to get false positive results and over diagnosing the HIT; this is the main disadvantage of ELISA test, but if ELISA is negative, (Figure 1) it will rule-out HIT [12].

Recently discovered an innovation, simple test, which can exclude HIT in 10 minutes. This is by LFIA, this test requires gold nanoparticles; by adding 5 micro liter of patients serum and two drops of buffer solution are pipetted into a disposable test unit (buffer contains human PF4+heparin) PF4 is biotinylated in the presence of heparin; specific IgG antibodies in patients serum will bind to the PF4+heparin buffer in the fluid membrane. While migrating through conjugated, gold nanoparticles, which than migrate to the capture zone of the analytical membrane which had an immobile antihuman IgG antibodies resulting in formation of the intense red line [13].

\section{Differential Diagnosis}

HIT has to be differentiated from disseminated intravascular coagulation (DIC), heparin toxicity, and hyper responsive thrombocytopenia. It is critical to differentiate these conditions from HIT as their management is totally different from HIT.

DIC is a pathologic activation of intravascular coagulation leading to thrombocytopenia and bleeding due to various diseases ranging from sepsis to trauma and obstetrical causes. In DIC the endovascular injury leads to small vascular thrombosis with consumption of coagulation factors and platelets. Thrombocytopenia of DIC can be differentiated from HIT by bleeding tendency, prolonged coagulation parameters, and elevated fibrinogen degradation, products [14].

Acute heparin toxicity is the heparin overdose, which can be life threatening and fatal. Common manifestations are bleeding from wound, mucosal membrane, and more critical intraventricular hemorrhage. It can be differentiated from HIT by bleeding, abnormally prolonged activated prothrombin time with thrombocytopenia [15].

Hyper responsive thrombocytopenia occurs in various inflammatory diseases, such as eczema, allergic rhinitis, and bronchial asthma. Particularly, the platelets are actively involved and consumed in acute bronchial asthma leading to bronchial hyper responsiveness, bronchoconstriction with airway inflammation, and thrombocytopenia. It can be differentiated from HIT by the signs and symptoms of primary etiology leading to hyperactive response [16].

\section{Management}

The management of HIT can be summarized by six 'a's [7].

1. Avoid and stop all heparin (any form, any route, heparin flush or heparinised catheters).

2. As early as possible start direct thrombin inhibitors.

3. Anti PF4 / heparin antibody test for confirmation of diagnosis.

4. Avoid platelet transfusion.

5. Await platelet recovery.

6. Assess thrombosis of lower extremities.

The highest risk period for the development of thrombosis is from the diagnosis of HIT to the starting of anti-thrombin agents. The use of direct thrombin inhibitors (DTI) is a corner stone in HIT therapy as it rapidly stops the thrombus storm. Commonly used DTI are Argatroban and Lepirudin. Argatroban is an L-arginine based molecule. It is shorter and reversible in binding with thrombin. Lepridin is a desulfated recombinant hirudin-like protein. It is eliminated through the renal system and needs adjustment of the dose in renal failure patients. There is no antidote for both DTI and it is necessary to adjust the dose to avoid coagulation disorders [17]. The warfarin therapy needed in HIT patients should be delayed until the platelet count is $>100 \times 103 /$ $\mu \mathrm{l}$ and DTI must be continued for at least five days in conjunction with warfarin therapy.

\section{Prevention}

To some extent HIT can be prevented by using heparin therapy for only short periods and starting warfarin early if there appears to be a need for prolonged anticoagulation; avoiding bovine and fractional heparin and using lower molecular weight heparin [5]. Avoiding heparin flush for central and arterial catheters, avoiding heparin lock, using heparin-free dialysis will decrease the incidence of HIT as well as coagulation disorders [18].

\section{Morbidity and Mortality}

Mortality in HIT patient is ranging from $20-30 \%$. HIT without thrombosis has mortality up to $21 \%$. In HIT patients treated with DTI the mortality decreases to $16 \%$ and the incidence of new thrombus decreases to $5.8 \%[19]$.

\section{Conclusion}

HIT is a distinct clinico-pathological syndrome, potentially limb and life threatening condition. It has a unique pathophysiology and testing. Low probability 4'T' score or LFIA will rule-out HIT in 10 minutes. It has a unique complication profile: Thromboemboli. HIT requires a unique management with the alternative anticoagulants; it is a unique thrombocytopenia, where the risk of thrombosis is more than that of bleeding. Ruling out of HIT antibodies is an important step in selecting most appropriate therapy. 


\section{References}

1. Cooney MF (2006) Heparin induced thrombocytopenia advances in diagnosis and treatment. Crit Care Nurse 26: 30-37.

2. Shaikh N (2011) Heparin induced thrombocytopenia. J Emerg Trauma Shock 4: $97-102$.

3. Warkentin TE and Kelton JG (2001) Delayed onset heparin induced thrombocytopenia and thrombosis. Ann Intern Med 135: 502-506.

4. Franchini M (2005) Heparin induced thrombocytopenia: an update. Thromb J J 3:14

5. Warkentin TE, Roberts RS, Hirsh J, Kelton JG (2003) An improved definition of immune heparin-induced thrombocytopenia in postoperative orthopedic patients. Arch Intern Med 163: 2518-2524.

6. Ganzer D, Gutezeit A, Mayer G (1999). Potential risk in drug prevention of thrombosis- low molecular weight heparin versus standard heparin. Z Orthop Ihre Grenzgeb 137: 457-461.

7. Greinacher A (1994) Heparin associated thrombocytopenia. Biomed Prog 7: 53-56

8. Burgess JK, Chang BH (1997) The platelet proaggregating and potentiating effect of unfractionated heparin, low molecular weight heparin and hepariniod in intensive care patients and healthy control. Eur J Haematol 58: 279-285.

9. Rhodes GR, Dixon RH, Silver D (1977) Heparin induced thrombocytopenia: Eight cases with thrombotic and hemorrhagic complications. Ann Surg 186: 752-758.

10. Warkentin TE, Levine MN, Hirsh J, Horsewood P, Roberts RS et al. (1995) HIT in patients treated with lower molecular weight heparin or fractional heparin. $\mathrm{N}$ Eng J Med 332: 1330-1335
11. Lo GK, Juhl D, Warkentin TE et al. (2006) Evaluation of pretest clinical score (4'T's) for diagnosis of HIT in two clinical settings. J Thrombosis Haemostat 4: 759-765.

12. Otis SA and Zehinder JL (2010) Heparin induced thrombocytopenia: Current status and diagnostic challenges. Am J Hematol 85: 700-706.

13. Kolde HJ, Postatni R, Mauracher S (2011) Rapid and simple IgG specific test for the exclusion of heparin induced thrombocytopenia (HIT). Clin Chem Lab Med 49: [Epub ahead of print].

14. Levi M (2008) The coagulant response in sepsis. Clin Chest Med 29: 627-642.

15. Zidane M, Schram MT, Planken FW, Molendijk WH, Rosendaal FR et al. (2000) Frequency of major hemorrhage in patients treated with unfractionated intravenous heparin for deep venous thrombosis or pulmonary embolism: A study in routine clinical practice. Arch Intern Med 160: 2369-2373.

16. Pichford SC, Momi S, Banglioni S, Casali L, Gianni S, et al. (2008) Allergen induces the migration of platelets to the lung tissue in allergic asthma. Am J Respir Crit Care Med 177: 604-612.

17. Rhodes GR, Dixon RH, Silver D (1977) Heparin induced thrombocytopenia: Eight cases with thrombotic and hemorrhagic complications. Ann Surg 186: 752-758.

18. Nisio MD, Middeldrop S, Buller HR (2005) Direct thrombin inhibitors. N Eng J Med 335: 1028-1240.

19. Amiral J, Bridey F, Dreyfus M, Vissoc AM, Fressinaud E, et al (1992) Platele factor 4 complex to heparin is target for antibodies generated in heparininduced thrombocytopenia. Thromb Haemost 68: 95-96.
This article was originally published in a special issue, Coagulation Disorders: Heparin Induced Thrombocyłopenia handled by Editor(s). Dr. Domenico Calcaterra, University of lowa, USA 